\title{
Scrutinising the Socio-Demographic Pattern of Parenting Practices and Parenting Styles in Upholding Child's Protection and Privacy to Address Paedophilia Issue
}

\author{
Siti Nur Fathanah Abd Hamid ${ }^{1}$, Yarina Ahmad ${ }^{1} \&$ Nor Suziwana Tahir ${ }^{1}$ \\ ${ }^{1}$ Faculty of Administrative Science \& Policy Studies, Universiti Teknologi MARA (UiTM), Malaysia \\ Correspondence: Yarina Ahmad, Faculty of Administrative Science \& Policy Studies, Universiti Teknologi MARA \\ (UiTM), Malaysia.
}

Received: May 1, 2019

Accepted: June 1, 2019

Online Published: July 9, 2019

doi:10.5430/rwe.v10n2p108

URL: https://doi.org/10.5430/rwe.v10n2p108

\begin{abstract}
Paedophilia issue has become a global issue around the world, including Malaysia. In today's era of globalisation and modernisation, the seriousness of paedophilia issue is undeniable. As the closest persons to children, parents have been recognised as the critical actor that contributes to children's protection and security. However, research related to "parenting practices" and "parenting styles" specifically to address the paedophilia issue remains limited in Malaysian context. Thus, a doctoral research, conducted by one of the authors, aimed to fill the gap. Based on the findings, this paper presents the socio-demographic and sociocultural pattern of Malaysian parents in upholding child protection and privacy to prevent paedophilia issue. A survey involving 900 parents representing the equal number of genders (male and female) and ethnicities (Malays, Chinese and Indian) was undertaken. Based on the statistical analysis, there were two key findings highlighted in this paper, which were: (1) the socio-demographic pattern revealed that female parents have higher interest in upholding the child protection and privacy, as compared to male parents; and (2) the socio-cultural pattern showed that Indian parents have high commitment in upholding the child protection and privacy, followed by Malay and Chinese parents. Although every parent has different approaches in upholding their children's protection and privacy; however, this paper argued that the socio-demographic and socio-cultural aspects are among the main indicators influencing parenting practices and parenting styles in Malaysia.
\end{abstract}

Keywords: Paedophilia, parenting practices, parenting styles, child protection and privacy

\section{Introduction}

The year 2014 has sparked an anger and grief among Malaysian citizens due to the abuse cases involving 23 children in the big city of Kuala Lumpur. This hideous crime was committed by a British paedophile who masqueraded as an English teacher who provided free English classes to the victims. However, studies proved that Malaysian parents seem to be forgotten about the issue that it has been washed away over the time. Although the roles and responsibilities of parents are important in child development and growth as well as child protection and privacy; parents still keep exposing their children to the sexual predators. Without thinking about the negative consequences, parents upload their children's pictures and videos on the internet, especially on social networking sites such as Facebook, Instagram and Twitter. There is no doubt that, in most situations, the internet can make people's lives easier; however, the negative consequences of misusing the internet are still open for more debates and discussions all over the world. Thus, parents, as the closest persons to children, should protect and secure their children privacy from being victimised by sexual predators including paedophiles.

Based on this main gap, one doctoral research is being undertaken entitled: "Do not publicise me; I may be the victim of paedophiles": The parenting practices and parenting styles in upholding the child protection and privacy in Malaysia. Based on the result gathered during the survey of this study, this paper aimed to present a part of the findings which can be divided into three main objectives of: 1) to identify the parents' behaviour in upholding child protection and privacy to prevent paedophilia issue; (2) To examine the socio-demographic patterns (gender and age groups) of parents in upholding child protection and privacy to prevent paedophilia issue; and (3) to examine the socio-cultural pattern (ethnics) of parents in upholding child protection and privacy to prevent paedophilia issue. The detail analysis and discussion is presented in the following sections and sub-sections. 


\section{Literature Review - The Parenting Practices and Parenting Styles in Upholding the Child Protection and Privacy to Address the Paedophilia Issue in Malaysia}

In today's globalised, modernised and digitalised world, social issues are becoming more complex and difficult to understand. In worst-case scenario, the issues become more serious when the victims are among children at young age. Children have been recognised as one of the vulnerable groups, in any part of the world, who require adequate protection, care, security, development and growth. This is because children do not have the capability and capacity to protect themselves, especially when dealing with the issue of child abuse. A study undertaken by Ahmad (2018) revealed that the child abuse issue in the world has a long history since $1860 \mathrm{~s}$, when the first term of 'battered child syndrome' was coined by Ambroise Tardieu, a professor of legal medicine in Paris, during that century. After cycles of discussions and debates among scholars and researchers regarding the term, there was a growing interest in child abuse and neglect issues in all over the world, including Malaysia. Ahmad (2018) further stated that the issue of child abuse in Malaysia gained significant prominence, and further it was catapulted into the public's attention in 1990 by the events and media attention surrounding the tragic death of 26-month-old B. Balasundaram who was brutally abused.

Since then, it is believed that the child abuse issue in Malaysia has undergone a series of evolution and engraved with a number of current challenges such as the disruptive technological advancement. Due to this situation, numerous types of child abuse have emerged in the country, such as paedophilia issue. History revealed that the paedophilia issue has existed since 1880s when the term was firstly discussed in a book entitled 'Psychopatia Sexualis: A clinical forensic study, written by Richard Kraftt-Ebing, a German sexologist and physician. However, after only more than a century, this issue received an attention and acknowledgement in Malaysia. Back in 2014, the first paedophilia case involving 23 Malaysian children sparked anger and grief among Malaysian societies (Mokgari \& Pwaka 2018). This case further received extensive coverage from media all over the world since the perpetrator is recognised as one of brutal paedophiles in the world. Richard Huckle, a British paedophile, committed the crime over Malaysian children aged between 6 months to 12 years old (The Star, 2016). Some of the victims were raped (14 charges) and sexually assaulted (21 charges). And in worst case scenario, Huckle uploaded the pictures and videos of abused children to be posted on the website known as the True Love Zone (The Star, 2016). This worrying situation has significantly influenced the children's development and growth because once the child is abused, the scar remains forever.

Although the seriousness of Huckle's paedophilic crime is undeniable and it gives million consequences to children's protection and privacy; however, this issue seems to be forgotten and washed away over the time. According to Datuk Dr. Amar Singh, a senior consultant paediatrician, many Malaysian parents still happily post the pictures of their children on social networking sites such as Facebook, Instagram and Twitter (The Star, 2017). Besides, some of Malaysian parents also use their children's pictures as profile images on messaging platform, including WhatsApp and WeChat. Without thinking about negative consequences, parents actually provide a rich access of child pornography to sexual predators including paedophiles who have sexual interest in children (The Star, 2017). Previously, children are highly exposed to risks and abuse in various settings and situations, including at home and school; however, the 'new trend' of paedophilia issue allows children to be virtually abused without anyone noticing through the production of child pornography materials (Mat Yunus, 2018; Maziku, 2016).

It takes a village to raise a child-This proverb portrays that the duty of protecting children is everyone's responsibility. However, among the community, this paper argued that 'parents', as the closest persons to children, have the biggest responsibility and obligation to protect and secure their children's privacy. In other countries such as the United Kingdom (Hawes \& Hooper, 2012), the United States (MBC, 2017), Australia (Sanders, 2015), Canada (Commit to Kids, 2008-2012) and Southeast Europe (Illieska \& Resavska, 2015; Khalifa, 2018), the roles of parents have been highly emphasised in protecting children, especially from sexual abuse issue including paedophilia. Each country has developed a specific guideline to assist and educate parents as well as protect children from being the victims of sexual abuse. However, literature revealed that Malaysia is still putting a lack of emphasis on developing specific guideline for parents. Based on this main gap, a doctoral research, conducted by one of the authors, aimed at exploring the 'parenting practices' and parenting styles' in upholding the child protection and privacy in Malaysia, specifically to prevent paedophilia issue. Thus, this paper presents the statistical findings related to socio-demographic and socio-cultural pattern of Malaysian parents in upholding child protection and privacy to prevent paedophilia issue.

\section{Methodology}

This study applied the quantitative approach through a general survey by using questionnaire. A total number of 900 parents were involved in this study which represented an equal number of genders (male and female parents) and 
ethnicities (Malay, Chines and Indian parents). The survey was conducted in three different areas in Kuala Lumpur which were Batu, Kuala Lumpur city and Petaling. Notably, these three main areas were selected based on the population distribution of the three main different ethnics. The selection of sample for this study was based on five main criteria as presented in Table 1. Although this study involved parents who lived in Kuala Lumpur; it could be generalised to Malaysian population. This is because; the population in Kuala Lumpur came from various people from other states in Malaysia. History showed that Kuala Lumpur has a diversified population since 1980s which resulted from the internal migration during that time; and the number still increased in 2000s (Hussain et al., 2015; Mishra, 2018). A high number of internal migrants (from other states such as Kedah, Penang, Kelantan, Terengganu, Sabah and Sarawak) to Kuala Lumpur have changed the landscape of its population distribution. Hence, the total number of samples involved in this study could be argued to represent the total population of Malaysia. Further, the findings of this study were analysed by using the Statistical Package for Social Science (SPSS) through frequency, descriptive, crosstabulation, T-Test and One-Way ANOVA analyses.

Table 1. Criteria for sample selection involving parents

\begin{tabular}{ll}
\hline Criteria & Number of samples \\
\hline Area & 300 respondents \\
Batu & 300 respondents \\
Kuala Lumpur & 300 respondents \\
Petaling & \\
Ethnicity & 300 respondents \\
Malay & 300 respondents \\
Chinese & 300 respondents \\
Indian & \\
Gender & 150 respondents for each area \\
Male & 150 respondents for each area \\
Female & \\
Age of parents & 300 respondents for each area \\
25 to 55 years old & \\
Age of children & 300 respondents for each area \\
Parents must have at least a child, & \\
aged 7 to 13 years old &
\end{tabular}

\section{Findings}

The presentation of findings derived from the quantitative results of this study is presented based on three main aspects, which are: (1) profile of respondents; (2) parents' behaviour in upholding child protection and privacy to prevent paedophilia issue; (3) socio-demographic pattern; and (4) socio-cultural pattern of parents in upholding child protection and privacy to prevent paedophilia issue in Malaysia, as stated in the following sub-sections.

\subsection{Profile of Respondents}

As indicated earlier, the number of parents participated in the survey represented the equal number of genders (450 male respondents and 450 female respondents) and three main ethnics (300 respondents represented each ethnic) in Malaysia. Based on the findings discovered from the quantitative results, the pattern of age among parents can be considered as similar. 
The majority of parents who involved in this study were among the parents aged between 36 to 40 years old (326 respondents). Since this study involved with parents who have at least one child, mostly, the status of respondents were found to be married ( 857 respondents). However, there were few respondents who were still single but already have children due to the adoption (10 respondents). In term of religion, all Malay parents were Muslims (300 respondents); while the other two ethnics were among Buddhism (274 respondents) and Hinduism (282 respondents). There was a small proportion of respondents who believed in other religions (37 respondents). In term of educational background, more than half of the percentage held tertiary level of education (584 respondents). Notably, most of respondents worked in various sectors. The highest was private sector (398 respondents), followed by public sector (248 respondents); and more than half of the respondents earned below RM5,000.00 (489 respondents). Further, the majority of respondents' households were around RM6000 and below. Table 2 showed the profile of respondents involved in this study.

Table 2. Demographic profile of respondents

\begin{tabular}{|c|c|c|}
\hline Profile & Total & Percentage $(\%)$ \\
\hline \multicolumn{3}{|l|}{ Gender } \\
\hline Male & 450 & 50.0 \\
\hline Female & 450 & 50.0 \\
\hline \multicolumn{3}{|l|}{ Age } \\
\hline 25-30 years old & 82 & 9.1 \\
\hline 31-35 years old & 155 & 17.2 \\
\hline $36-40$ years old & 326 & 36.2 \\
\hline 41-45 years old & 197 & 22.0 \\
\hline $46-50$ years old & 103 & 11.4 \\
\hline 51-55 years old & 37 & 4.1 \\
\hline \multicolumn{3}{|l|}{ Status } \\
\hline Single & 10 & 1.1 \\
\hline Married & 857 & 95.2 \\
\hline Divorced & 23 & 2.6 \\
\hline Widowed & 10 & 1.1 \\
\hline \multicolumn{3}{|l|}{ Religion } \\
\hline Islam & 307 & 34.1 \\
\hline Buddha & 274 & 30.4 \\
\hline Hindu & 282 & 31.3 \\
\hline Christian & 35 & 4.0 \\
\hline Others & 2 & 0.2 \\
\hline \multicolumn{3}{|l|}{ Education } \\
\hline Never been to school & 3 & 0.3 \\
\hline Primary School & 32 & 3.6 \\
\hline Secondary School & 227 & 25.2 \\
\hline Malaysian Higher School Certificate & 54 & 6.0 \\
\hline Certificate & 54 & 6.0 \\
\hline Diploma & 203 & 22.6 \\
\hline Bachelor Degree & 279 & 31.0 \\
\hline Master Degree & 38 & 4.2 \\
\hline
\end{tabular}


Doctoral Degree

Professional Qualification

Others

\section{Occupation}

Not working

Government

Private

Non-Governmental Organisation

Self-employed

Others

\section{Household Income}

No income

Below MYR1,000

MYR1,001-MYR2,000

MYR2,001-MYR3,000

MYR3,001-MYR4,000

MYR4,001-MYR5,000

MYR5,001-MYR6,000

MYR6,001-MYR7,000

MYR7,001-MYR8,000

MYR8,001-MYR9,000

MYR9,001-MYR10,000

MYR10,001 and above

\section{Years Staying in Kuala Lumpur}

Below 5 years

5 years -10 years

10 years and above

\section{Number of Child}

1-4 children

5-8 children

\section{Research Objective 1: To Identify the Parents' Behaviour in Upholding the Child Protection and Privacy to Prevent the Paedophilia Issue}

The first objective explores the level of parents' behaviour in upholding child protection and privacy to prevent paedophilia issue. Thirteen (13) questions related to parents' behaviour in in upholding child protection and privacy were adopted from the 54 principles of CRC. These 13 questions were applied in the context of preventing paedophilia issue. Each question was measured through 5 (five) Likert scale questions [Strongly disagree (1) to strongly agree (5)]. The findings of level of parents' behaviour in upholding child protection and privacy to prevent paedophilia issue are presented in Table 3. The overall findings indicated that the level of parents' behaviour in upholding child protection and privacy to prevent paedophilia issue is considered good (Mean=4.6841, Std. deviation=0.668). The highest mean value was recorded for the role of parents in ensuring that the "children must be protected from engaging in any unlawful sexual activities" (Mean=4.72, Std. deviation=0.667); followed by "protecting children from engaging in any unlawful sexual activities" (Mean=4.71, Std. deviation=0.622); "protecting children from engaging in prostitution or other unlawful sexual practices" (Mean=4.71, Std. deviation=0.642); and "children must be protected for their best interests (Mean=4.70, Std. deviation $=0.608$ ). 
Table 3. Level of parents' behaviour in upholding the child protection and privacy

\begin{tabular}{lcc}
\hline Items & Mean & Std. Deviation \\
\hline Children must be protected from discrimination. & 4.70 & 0.609 \\
Children must be protected for their best interests. & 4.66 & 0.601 \\
Child protection and care is necessary for the children's well-being. & 4.68 & 0.584 \\
Children need appropriate direction and guidance from & 4.65 & 0.609 \\
parents/guardians/responsible adults. & 4.67 & 0.611 \\
The children's rights to survival and development must be uphold. & 4.61 & 0.677 \\
Children's views and voices must be heard. & 4.64 & 0.640 \\
Parents have the primary responsibilities for the upbringing and & 4.67 & 0.642 \\
development of their children. & 4.63 & 0.668 \\
Children need to be protected from abuse and harm. & 4.68 & 0.667 \\
Children should not be deprived from his/her family development. & 4.72 & 0.622 \\
Children should not be sexually exploited and sexually abused. & & \\
Children must be protected from engaging in any unlawful sexual & 4.72 & 0.642 \\
activities. & & \\
Children must be protected from engaging in prostitution or other & 4.71 & 0.688 \\
unlawful sexual practices. & 4.68 & 0.461 \\
Children must be protected from being exploited in pornographic & & \\
performance and materials. & &
\end{tabular}

Research Objective 2: To Examine the Socio-Demographic Patterns (gender and Age Groups) of Parents in Upholding the Child Protection and Privacy to Prevent the Paedophilia Issue in Malaysia

In answering the first objective, a separate independent sample T-Test analysis was conducted to examine the pattern of "gender" and "age groups" among parents in upholding child protection and privacy to prevent paedophilia issue in Malaysia. The findings are presented in Table 4. These findings revealed that there was no significant difference between "gender" and parents' behaviour in upholding child protection and privacy to prevent paedophilia issue in Malaysia [t=-1.737, $\mathrm{df}=898, \mathrm{p}=0.083(\mathrm{p}>0.05)]$. Notably, the respondents' "age groups" found significant difference with parents' behaviour in upholding the child protection and privacy to prevent paedophilia issue in Malaysia $[t=3.580, d f=580.727, p=0.000(p>0.01)]$. The mean value for younger age group parents $(25-40$ years old) in upholding child protection and privacy to prevent paedophilia issue was found higher (Mean=4.7289, Std. deviation=0.41106) than older age parents $(41-55$ years old $)($ Mean=4.6091, Std. deviation=0.52539).

Table 4. The socio-demographic patterns (gender and age groups) of parents in upholding the child protection and privacy to prevent the paedophilia issue

\begin{tabular}{|c|c|c|c|c|c|}
\hline Variable & Levene's Test & $\mathbf{t}$ & df & $\begin{array}{c}\text { Sig. } \\
\text { (2-tailed) }\end{array}$ & $\begin{array}{c}\text { Mean } \\
\text { difference }\end{array}$ \\
\hline $\begin{array}{l}\text { Pattern of "gender" among parents } \\
\text { in upholding the child protection } \\
\text { and privacy to prevent the } \\
\text { paedophilia issue in Malaysia. }\end{array}$ & $\begin{array}{c}0.418 \\
\text { (Homogeneity is } \\
\text { assumed) }\end{array}$ & -1.737 & 898.000 & $\begin{array}{c}0.083 \\
\text { (Not significant) }\end{array}$ & -0.05328 \\
\hline $\begin{array}{l}\text { Pattern of "age groups" among } \\
\text { parents in upholding the child } \\
\text { protection and privacy to prevent } \\
\text { the paedophilia issue in } \\
\text { Malaysia. *age groups of parents are categorised } \\
\text { into two: }\end{array}$ & $\begin{array}{c}0.000 \\
\text { (Homogeneity of } \\
\text { variance not assumed) }\end{array}$ & 3.580 & 580.727 & $0.000^{\text {(Significant) }}$ & 0.11978 \\
\hline $\begin{array}{l}\text { 1) Young parents: } 25-40 \text { years old } \\
\text { 2) Older parents: } 41-55 \text { years old }\end{array}$ & & & & & \\
\hline
\end{tabular}


Research Objective 3: To Examine the Socio-Cultural Pattern (Ethnics) of Parents in Upholding the Child Protection and Privacy to Prevent the Paedophilia Issue in Malaysia

In answering research objective two, One-Way ANOVA analysis was conducted. The finding of this analysis is presented in Table 5. Based on the ANOVA findings, there was a significant difference between three main ethnic groups with parents' behaviour in upholding child protection and privacy to prevent paedophilia issue in Malaysia $[\mathrm{F}=9.498, \mathrm{df}=2, \mathrm{p}=0.000(\mathrm{p}<0.01)]$. The Levene's test value was less than 0.05 indicating that homogeneity of variance was not assumed. Therefore, the Pos Hoc findings of Tamhane were used to compare each ethnic group. The significant findings were found between: (1) Chinese and Indian $[\mathrm{p}=0.000(\mathrm{p}<0.01)$, mean difference $=$ $-0.16188]$; (2) Indian and Malay $[\mathrm{p}=0.007(\mathrm{p}<0.01)$, mean difference $=-0.09205]$.

Table 5. The socio-cultural pattern (ethnics) of parents in upholding the child protection and privacy to prevent the Paedophilia issue

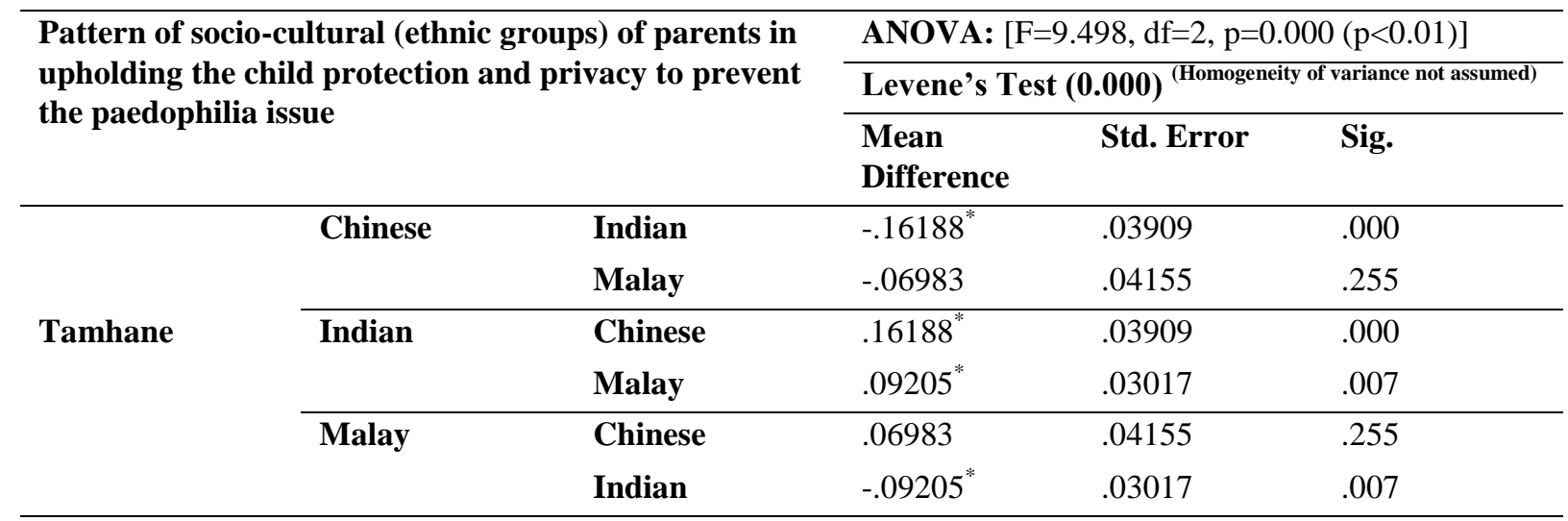

\section{Discussion and Conclusion}

The findings of this study can be divided into three main objectives which were: (1) to identify the parents' behaviour in upholding child protection and privacy to prevent paedophilia issue; (2) To examine the socio-demographic patterns (gender and age groups) of parents in upholding child protection and privacy to prevent paedophilia issue; and (3) to examine the socio-cultural pattern (ethnics) of parents in upholding child protection and privacy to prevent paedophilia issue. Based on the findings of the first objective, this study discovered that overall level of parents' behaviour in upholding child protection and privacy to prevent paedophilia issue is considered good. This indicates that Malaysian parents are becoming more aware of child protection and privacy. This study believed that the complexity of social issues involving children has called parents to strengthen their parenting practices in order to prevent their children from being the victims of child sexual abuse.

Further, in answering the research objective two and three, this study also conducted two different analyses that aimed to examine the socio-demographic and socio-cultural patterns of parents in upholding child protection and privacy to prevent paedophilia issue in Malaysia. As indicated earlier, the independent sample T-test was undertaken to scrutinise the socio-demographic pattern of parents. Based on the findings, this study discovered that there is no significant difference between "gender" and behaviour of parents in upholding child protection and privacy in Malaysia. The findings of this study showed different pattern which "gender" is not a significant predictor in examining parents' behaviour in the context of this study. Previously, research on parenting practices and styles revealed that male and female parents showed a significant different in raising their children; however, this study believed that due to the negative implications of rapid development, globalisation, modernisation and other constraints faced by today's parents, both need to undertake almost similar responsibility towards their children, especially in terms of the child protection and privacy. Although the role theory can explain the differences between fathers and mothers; however, through gender socialisation, male and female parents are continuously learning the social expectations associated with one's sex (Garcia \& T. de Guzman, 2017; Mizad, et al. 2018).

On the other hand, "age group" showed contradict findings whereby it has a significant difference with the parents' behaviour in upholding child protection and privacy to prevent paedophilia issue in Malaysia. In this case, protecting children from sexual predators, especially paedophiles, can be undertaken in physical reality. However, it may become more difficult to protect and secure children's privacy in the virtual reality. Due to the globalisation and 
modernisation, the rapid technological advancement gives an impact towards child development and growth. According to an organisation in the United Kingdom, The Lucy Faithful Foundation (n.d.), children and young people often use computers and mobile phones from an early age at home and in school. In some worrying situations, their knowledge and understanding of how it works may be greater than their parents and carers (The Lucy Faithful Foundation (n.d.). This situation portrayed that "age group" can be considered as one of the indicators which can influence the parents' behaviour in protecting and securing children's privacy.

Further, One-Way ANOVA analysis was undertaken to examine the socio-cultural pattern (ethnics) of parents in upholding child protection and privacy to prevent paedophilia issue in Malaysia. The findings of this study discovered two categories which have significant differences which were: (1) Chinese and Indian; and (2) Indian and Malay. Although Colby (2006) undertaken a slightly different study that proved culture is one of the important factors to be taken into account when labelling certain acts as abusive or neglectful; however, it is argued that different culture can also determine different behaviour of parents in protecting their children from paedophiles. An initiative of understanding child abuse issue in Malaysia undertaken by Ahmad (2018) showed that the findings of this study are consistent with previous research, whereby previous authors stated that culture have significant influenced on parenting practices.

Based on the above analysis and discussion, this study argued that "parents", as the closest persons to children, need to protect and secure their children's privacy from any form of abuse including paedophilia. The roles of parents do not limit only to homes; they have big responsibilities beyond their comfort zones; and the most important thing is parents need to protect and secure children as an Amanah (trust) rather than the property. Further, the relevant information gathered throughout the study can be utilised by the relevant agencies, especially the government and non-governmental organisations, in promoting and educating parents and their children on child protection and privacy in this country.

\section{Acknowledgement}

We wish to acknowledge the Ministry of Higher Education (MoHE), Fundamental ResearchGrant Scheme (FRGS) [File No: 600-RMI/FRGS 5/3 (0042/2016)] and Universiti TeknologiMARA (UiTM) for the research grant enabling this study to be carried out. Besides, we would like to express our sincere gratitude to the coordinator and participants of FSPPP-Graduate Researchers in Print for the constructive comments and ideas on the improvement of this paper as well as to FSPP for the support and encouragement.

\section{References}

Ahmad, Y. (2018). Empirical Evidence on Child Abuse in the Malaysian Context. Selangor, Malaysia: UiTM Press.

Commit to Kids. (2008-2012). Parent guide: Helping organizations prevent child sexual abuse. Retrieved from https://www.protectchildren.ca/pdfs/C2K_ParentGuide_en.pdf

Corby, B. (2006). Child abuse: Towards a knowledge base. Open University Press.

Garcia, A., \& T. de Guzman, M. R. (2017). Parenting Styles, Gender Differences. In Nadal, K. L. (Ed.), The SAGE Encyclopedia of Psychology and Gender. Thousand Oaks: SAGE Publications, Inc.

Hawes, M. E., \& Hooper, L. (2012). Enough Abuse: Parental guidelines for identifying and managing the issues created by the "grooming" and sexual abuse of children under the age of sixteen" (4th ed.). Retrieved from http://www.dare2care.org.uk/wp-content/uploads/2015/12/Bookletprint-2012-PDF.pdf

Hussain, N. E., Abdullah, N., \& Abdullah, H. (2015). The relationship between internal migration and its migration factors: Case study in Malaysia. Journal of Malaysian Economics, 49(2), 121-133. https://doi.org/10.17576/JEM-2015-4902-10

Ilieska, L. P., \& Resavska, T. (2015). Parents' guide to protecting children's privacy and personal data on the internet. Retrieved from http://metamorphosis.org.mk/wp-content/uploads/ 2015/06/Guide-for-Parents.pdf

Khalifa, T. B. (2018). The Politics of Fear in the US Political Discourse about Migration: An Argument-Based $\begin{array}{lllll}\text { Approach. Humanities and Social } & \text { Sciences }\end{array}$ https://doi.org/10.18488/journal.73.2018.62.16.30

Krafft-Ebing, R. (1886). Psychopathia Sexualis. New York: Rebman Company. Maidenhead, New York.

May Yunus, N. K., Abu Yazid, Z. N., Abd Aziz, N. N., Ali, R., \& Ahmad, S. H. (2018). Influences of paedophilic and family environmental factors on paedophilia: A preliminary study. Proceedings of Putrajaya International 
Conference on Children, Women, Elderly and People with Disabilities. Zes Roukman Resources: Bandar Baru Bangi, Malaysia.

Maziku, P. (2016). Effects of Non Tariff Barriers on Maize Trade in Mbozi and Momba Districts of Tanzania. International Journal of Economics, Business and Management Studies, 3(1), 1-11.

MBC (2017). Protecting children from pedophiles (3rd ed.). United States of America: M. B. Cowan.

Mishra, R. (2018). Financial Literacy, Risk Tolerance and Stock Market Participation. Asian Economic and Financial Review, 8(12), 1457-1471. https://doi.org/10.18488/journal.aefr.2018.812.1457.1471

Mizad, M., Yusoff, Z. S., Sayadi, Z. A., Latif, A. A., \& Sukiman, S. L. (2018). Students Readiness and Motivation to Use Mobile Phone for Learning English at Higher Learning Institution. International Journal of Asian Social Science, 8(11), 1077-1087. https://doi.org/10.18488/journal.1.2018.811.1077.1087

Mokgari, M. T., \& Pwaka, O. (2018). An Evaluation of Effectiveness of Oversight Committees: A Case of City of Johannesburg, Section 79 Committees. International Journal of Public Policy and Administration Research, 5(2), 48-67. https://doi.org/10.18488/journal.74.2018.52.48.67

Sanders, J. (2015). Body Safety Education: A parents' guide to protecting the children from sexual abuse. Victoria, Australia: UpLoad Publishing Pty Ltd.

The Lucy Faithfull Foundation. (n.d.). The Internet and children... What's the problem?. The Lucy Faithful Foundation: Alvechurch, Birmingham.

The Star. (2016b, June 6). Paedophile Richard Huckle who abused Malaysian children jailed for life. The Star Online. Retrieved from http://www.thestar.com.my/news/nation/2016/06/06/paedophilerichardhucklewhoabusedmalaysianchildrenjaile dforlife/

The Star. (2017, January 13). Parents still exposing kids to predators. The Star Online. Retrieved from http://www.thestar.com.my/news/nation/2017/01/13/parentsstillexposingkidstopredatorsexpertpaedophileshunti ngforphotosofchildrenonsocial/ 